\title{
New Punctaporonins from Two Fungicolous Isolates of
}

\section{Pestalotiopsis Sp.}

In Hyun Hwang, ${ }^{a}$ Donald T. Wicklow, ${ }^{\mathrm{b}}$ James B. Gloer ${ }^{\mathrm{a}, *}$

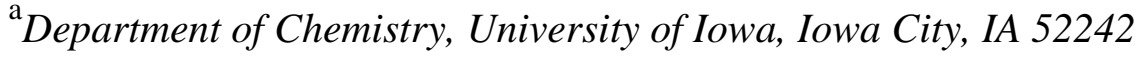

${ }^{\mathrm{b}}$ Bacterial Foodborne Pathogens \& Mycology Research Unit, Agricultural Research

Service, National Center for Agricultural Utilization Research, USDA, Peoria, IL 61604

* Corresponding authors at: Department of Chemistry, University of Iowa, Iowa City, IA 52242. Tel: 319-335-1361.

E-mail address: james-gloer@uiowa.edu (J. B. Gloer) 


\begin{abstract}
Seven new caryophyllene sesquiterpenoids $(\mathbf{5}-\mathbf{1 1})$ were isolated during investigation of two fungicolous isolates of Pestalotiopsis sp. and identified as punctaporonin analogues. The structures of these compounds were mainly assigned by analysis of NMR and HRMS data. Compounds 5, 6, and $\mathbf{7}$ are 13-hydroxy analogues of 6-hydroxypunctaporonins A, $\mathrm{B}$, and $\mathrm{E}$, respectively, and compound $\mathbf{8}$ is a 6-hydroxy analogue of punctaporonin $\mathrm{D}$. Compounds 9 and $\mathbf{1 1}$ are ketone-containing analogues of 6-hydroxypunctaporonin A and fuscoatrol A, respectively, and compound $\mathbf{1 0}$ is a 9-methoxy derivative of $\mathbf{8}$. The names punctaporonins $\mathrm{N}, \mathrm{O}$, and $\mathrm{P}$ are proposed for compounds $\mathbf{9}, \mathbf{1 0}$, and $\mathbf{1 1}$, respectively. Antibacterial activity associated with the extract was attributed to the presence of known punctaporonins as major metabolites.
\end{abstract}

Keywords:

Caryophyllene; Sesquiterpenoids; Fungicolous; Fungi; Pestalotiopsis; Punctaporonins 


\section{Introduction}

Caryophyllene and various analogues and derivatives thereof have been isolated from both plants and fungi (Collado et al., 1998). A characteristic feature of caryophyllene-related structures is a bicyclic ring system consisting of trans-fused fourand nine-membered rings. Tricyclic ring systems are sometimes formed by cross-ring linkages of the nine-membered ring (Collado et al., 1998). In the late 1980's, a series of oxidized caryophyllene analogues was reported from cultures of the fungus Poronia punctata. The first members of the series were initially referred to as punctatins, but the names were later changed to punctaporonins (Anderson et al., 1988; Poyser et al., 1986). Since then, numerous related, oxidized caryophyllene-type sesquiterpenoids have been reported from fungi, including 6-hydroxypunctaporonins and pestalotiopsins from Pestalotiopsis spp. (Deyrup et al., 2006; Pulici et al., 1996), fuscoatrol A from Humicola fuscoatra (Smetanina et al., 2004), Sch 725432, Sch 601253, Sch 601254, and Sch 725434 from Chrysosporium pilosum (Yang et al., 2009), cytosporinols from Cytospora sp. (Li et al., 2012), and punctaporonins $\mathrm{H}$ - M from Hansfordia sinuosae (Wu et al., 2014). Despite the unique and diverse chemistry associated with these compounds, their biological properties have been of limited interest to date, though some pestalotiopsins show immunosuppressive and cytotoxic activities and punctaporonin $\mathrm{K}$ reduces triglycerides and total cholesterol levels in cells (Pulici et al., 1996; Wu et al., 2014; Takao et al., 2009).

In the course of our studies of fungicolous fungi as sources of new bioactive natural products (Deyrup et al., 2006; Gloer, 2007; Hwang et al., 2015; Shim et al., 2011), the ethyl acetate extract of cultures of a fungicolous isolate of Pestalotiopsis sp. (MYC- 
709) obtained from the surface of a polypore collected in Georgia, USA showed antimicrobial activity. Chemical investigation of the extract resulted in discovery of pestaloporonins $\mathrm{A}-\mathrm{C}$, three related sesquiterpenoids containing new ring systems and/or skeletons (Hwang et al., 2015). However, NMR data revealed the extract to be exceptionally rich in terpenoid metabolites, suggesting that more in-depth studies might be fruitful. Further studies of this isolate afforded four known caryophyllene sesquiterpenoids $(\mathbf{1}-\mathbf{4})$ and seven new analogues $(\mathbf{5}-\mathbf{1 1})$. Details regarding the isolation and structure elucidation of these metabolites are described here. Upon completion of this work, efforts to identify this Pestalotiopsis isolate to species were met with the discovery that the corresponding stored cultures were no longer viable. However, similarities in the metabolites encountered with those reported earlier by our group from another fungicolous isolate of Pestalotiopsis $(P$. disseminata $\mathrm{MYC}-1444=$ NRRL 36915; deposited in the NRRL collection at the USDA National Center for Agricultural Utilization Research) led us to analyze the latter for the presence of the new compounds described above. Four of the same new compounds $(6-9)$ were found in the corresponding extract, along with the previously reported compounds $\mathbf{1}-\mathbf{3}$ (Deyrup et al., 2006). Minor peaks that could correspond to 4, 5, 10, and 11 were also present, but the complexity of the extract precluded definitive detection. These observations indicate that Pestalotiopsis sp. MYC-709 was very likely an isolate of $P$. disseminata, but more importantly, that most, if not all, of the same compounds could be obtained from a culture that is viable and accessible in the NRRL collection. 


\section{Results and discussion}

The acetonitrile-soluble portion of the crude ethyl acetate extract from solidsubstrate fermentation cultures of Pestalotiopsis sp. MYC-709 was fractionated using silica gel. Further purification with reversed-phase HPLC led to the isolation of new caryophyllene sesquiterpenoids $\mathbf{5}-\mathbf{1 1}$, together with the known metabolites, 6hydroxypunctaporonins E (1), A (2), and B (3), and fuscoatrol A (4). Compounds 5, 6, and 7 are 13-hydroxy analogues of 6-hydroxypunctaporonins A, B, and E, respectively. Compound $\mathbf{8}$ is a 6-hydroxy analogue of punctaporonin D, and its 9-methoxy derivative (10) was also encountered. Compounds 9 and $\mathbf{1 1}$ are oxidized analogues of 6hydroxypunctaporonin A and fuscoatrol A, respectively.

6-Hydroxypunctaporonin E (1) crystallized from methanol after HPLC

purification. The ${ }^{1} \mathrm{H}$ NMR spectrum showed signals typical of punctaporonins, including distinctive cis-coupled $(J=5.6 \mathrm{~Hz})$ olefinic protons $(\mathrm{H}-9$ and $\mathrm{H}-10)$, an isolated oxygenated methylene unit $\left(\mathrm{H}_{2}-12\right)$, and three methyl singlets $\left(\mathrm{H}_{3}-13, \mathrm{H}_{3}-14\right.$, and $\left.\mathrm{H}_{3}-15\right)$. In addition, two oxygenated methine signals (H-6 and H-11) were observed. Comparison of the ${ }^{1} \mathrm{H}$ NMR and specific rotation data with those of an authentic standard enabled identification of this compound as $\mathbf{1}$ (Deyrup et al., 2006). Compounds $\mathbf{2}-\mathbf{4}$ were similarly identified by NMR and MS comparison to available standards and/or literature data (Deyrup et al., 2006; Pulici et al., 1996; Smetanina et al., 2004). Fuscoatrol A (4) lacks a ring closure characteristic of the punctaporonins, and appears in solution as a 3:1 equilibrium mixture of two conformational isomers. This observation is consistent with the literature report of 4 (Smetanina et al., 2004). 
HRESIMS analysis of new compound $\mathbf{5}$ gave a pseudomolecular ion at $\mathrm{m} / \mathrm{z}$ $283.1542[\mathrm{M}-\mathrm{H}]^{-}$corresponding to the molecular formula $\mathrm{C}_{15} \mathrm{H}_{24} \mathrm{O}_{5}$ (four degrees of unsaturation). The ${ }^{1} \mathrm{H}$ NMR spectrum closely resembled that of $\mathbf{2}$, including fortuitously coincident signals for two olefinic protons, an isolated oxygenated methylene, and two oxygenated methines. The relatively small $(9.6 \mathrm{~Hz})$ geminal coupling between the two C-3 protons was consistent with retention of the cyclobutane unit (Deyrup et al., 2006). However, the data for 5 (Table 1) displayed one less methyl singlet, instead showing an oxygenated methylene signal at $\delta_{\mathrm{H}} 3.67\left(\mathrm{H}_{2}-13\right)$, suggesting replacement of one of the methyl groups of $\mathbf{2}$ with a $\mathrm{CH}_{2} \mathrm{OH}$ unit. This hypothesis was consistent with the presence of one additional oxygen atom in the molecular formula relative to that of $\mathbf{2}$, and was supported by analysis of ${ }^{13} \mathrm{C}$ NMR and HSQC data, which showed the presence of a disubstituted olefin unit, one oxygenated quaternary carbon, two oxygenated methine carbons, and two oxygenated methylene carbons. The additional hydroxy group relative to $\mathbf{2}$ was placed at C-13 by analysis of NOESY data (see below) and HMBC correlations from $\mathrm{H}_{3}-14$ to $\mathrm{C}-13$ as well as from $\mathrm{H}_{2}-13$ to $\mathrm{C}-3, \mathrm{C}-4, \mathrm{C}-5$, and $\mathrm{C}-14$. The remainder of the structure was confirmed to match that of $\mathbf{2}$ on the basis of HMBC correlations summarized in Figure 1.

The NOESY data for 5 (Fig. 2) were analogous to those of $\mathbf{2}$ (Deyrup et al., 2006), except that correlations of new oxymethylene protons $\mathrm{H}_{2}-13$ with $\mathrm{H}-2, \mathrm{H}-3 \mathrm{~b}$, and $\mathrm{H}-6$ indicated that this hydroxymethylene group $\left(\mathrm{CH}_{2}-13\right)$ is oriented as shown. Correlations of $\mathrm{H}-12 \mathrm{a}$ with $\mathrm{H}-3 \mathrm{a}$ and $\mathrm{H}_{3}-15$, and of $\mathrm{H}_{3}-15$ with $\mathrm{H}-9$ placed all of these hydrogens on the opposite face of the ring system relative to $\mathrm{CH}_{2}-13$. Because all of the previously known 6-hydroxypunctaporonin derivatives were also encountered in this extract, the 
absolute configuration of $\mathbf{5}$ was assumed to match the relevant features of 6hydroxypunctaporonin A $(1 S, 2 R, 5 S, 6 S, 8 S, 9 R)$ (Deyrup et al., 2006). The new stereogenic center at C-4 was assigned the $R$-configuration based on the relative configuration assigned by interpretation of the NOESY data. The trivial name 6,13dihydroxypunctaporonin A was proposed for compound $\mathbf{5}$.

Compound $\mathbf{6}$ was recognized as an isomer of $\mathbf{5}$ on the basis of HRESIMS data. Furthermore, the ${ }^{1} \mathrm{H}$ and ${ }^{13} \mathrm{C}$ NMR data for $\mathbf{6}$ were very similar to those for $\mathbf{3}$, with the only evident difference being replacement of one of the methyl singlets with an $\mathrm{AB}$ pattern characteristic of an oxygenated $\mathrm{CH}_{2}$ unit, indicating replacement of one of the geminal methyls of $\mathbf{3}$ with an isolated $\mathrm{CH}_{2} \mathrm{OH}$ group, as was the case for $\mathbf{5}$. As expected, relevant HMBC correlations from $\mathrm{H}_{3}-14$ to $\mathrm{C}-13$ and from $\mathrm{H}_{2}-13$ to $\mathrm{C}-3, \mathrm{C}-4, \mathrm{C}-5$, and C14 again located the new hydroxy group at C-13, thereby establishing the gross structure of 6 as shown.

The relative configuration of $\mathbf{6}$ was determined to be analogous to that of $\mathbf{3}$ by analysis of NOESY data (Deyrup et al., 2006). Specifically, correlations of H-2 with H-6 and $\mathrm{H}-10$, and of $\mathrm{H}_{3}-15$ with $\mathrm{H}-11$ indicated 6 that possesses the same trans-fused bicyclic system with analogous dispositions of the substituents of the nine-membered ring (Deyrup et al., 2006). The $E$-configuration of the C-1/C-11 olefin was confirmed by a cross-peak between $\mathrm{H}-12 \mathrm{~b}$ and $\mathrm{H}-11$. In addition, the $J_{\mathrm{H} 9-\mathrm{H} 10}$ value $(J=13 \mathrm{~Hz})$ is consistent with the literature report of $\mathbf{3}$, supporting the Z-configuration for the C-9/C-10 olefin (Deyrup et al., 2006). As was the case for 5, $\mathrm{H}_{2}-13$ correlated to H-2 and H-6, placing the hydroxylated $\mathrm{CH}_{2}-13$ on the same face of the ring system with these hydrogen atoms, leading to the identification of $\mathbf{6}$ as 6,13-dihydroxypunctaporonin B. The absolute 
configuration is proposed to be analogous to that previously assigned for $\mathbf{3}$ (Deyrup et al., 2006).

${ }^{1} \mathrm{H}$ and ${ }^{13} \mathrm{C}$ NMR data for compound 7 resembled those of $\mathbf{1}$, including the characteristic $6 \mathrm{~Hz} J$-value for the cis-olefinic protons. HRESIMS data indicated that 7 is an isomer of the dihydroxylated punctaporonin analogues 5 and 6. Again, as was the case for 5 and 6, HMBC data revealed that C-13 was hydroxylated. In addition, HMBC correlations of $\mathrm{H}_{3}-15$ with olefinic carbon $\mathrm{C}-9$ and of $\mathrm{H}-2$ with oxygenated methine carbon $\mathrm{C}-11$ showed that $\mathbf{7}$ is a regioisomer of $\mathbf{5}$, in which the allylic alcohol unit is transposed from its position in $\mathbf{5}$. The NOESY data for $\mathbf{7}$ were analogous to those of $\mathbf{1}$. $\mathrm{H}_{2}-13$ again correlated to $\mathrm{H}-2$ and $\mathrm{H}-6$, establishing the relative orientation of the new $\mathrm{CH}_{2} \mathrm{OH}$ unit as shown in 7. The absolute configuration was presumed to be analogous to that of 1 (Deyrup et al., 2006), and this metabolite was given the name 6,13dihydroxypunctaporonin E.

Compound 8 is another 6-hydroxypunctaporonin isomer. The ${ }^{1} \mathrm{H}$ NMR spectrum of $\mathbf{8}$ was nearly identical to that of $\mathbf{2}$, except for a significant downfield shift in the signal for $\mathrm{H}-9$, and slightly upfield shifts in the signals for $\mathrm{H}-2$ and $\mathrm{H}-6$. HMBC data revealed the connectivity of $\mathbf{8}$ to be identical to that of $\mathbf{2}$. However, NOESY correlations of H-9 with $\mathrm{H}-2$ and $\mathrm{H}-6$ showed that the relative configuration of 8 at C-9 is inverted relative to that of 2 (Fig. 3). This stereochemical difference was consistent with a significant difference in the specific rotation observed for $\mathbf{8}(+104 ; c 0.15, \mathrm{MeOH})$ relative to that of 2 (-11; $c$ 0.07, MeOH; Deyrup et al., 2006). Thus, 8 differs from the known compound punctaporonin D only by addition of a hydroxy group at C-6 (Anderson et al., 1988; Poyser et al., 1986). It was therefore assigned the trivial name 6-hydroxypunctaporonin 
D. Recently, the 6-O-acetyl analogue of this compound was reported from the spongeassociated fungus Hansfordia sinuosae and assigned the name punctaporonin $\mathrm{M}(\mathrm{Wu}$ et al., 2014). The absolute configuration was presumed to be analogous to that of $\mathbf{2}$ except for the inverted stereocenter at C-9 (Deyrup et al., 2006).

The molecular formula of 9 was assigned as $\mathrm{C}_{15} \mathrm{H}_{22} \mathrm{O}_{4}$ on the basis of HRESIMS data. The NMR data for 9 displayed close similarity with those of the 6hydroxypunctaporonins except for changes in the signals corresponding to positions 9,10 , and 11 (Tables 1 and 2), which suggested the presence of an $\alpha, \beta$-unsaturated ketone moiety rather than an allylic alcohol unit. The presence of such a unit was consistent with the UV spectrum, and with the five degrees of unsaturation indicated by the molecular formula. Key HMBC correlations from $\mathrm{H}_{3}-15$ to ketone carbon C-9 and from $\mathrm{H}_{2}-12$ to olefinic carbon C-11 enabled assignment of the regiochemistry of the $\alpha, \beta-$ unsaturated ketone moiety as shown in 9. Oxidation of a sample of $\mathbf{2}$ using PCC and pyrazole afforded a product with NMR data identical to those of $\mathbf{9}$ (Parish et al., 1984). Therefore, the relative and absolute configurations were assigned to match those of $\mathbf{2}$ (Deyrup et al., 2006). The name punctaporonin $\mathrm{N}$ was assigned to compound 9.

Compound $\mathbf{1 0}$ was determined to have the molecular formula $\mathrm{C}_{16} \mathrm{H}_{26} \mathrm{O}_{4}$ on the basis of HRESIMS data. The ${ }^{1} \mathrm{H}$ NMR spectrum of $\mathbf{1 0}$ was nearly identical to those of $\mathbf{8}$ and 2, except for the presence of a signal for a methoxy group. HMBC data revealed that the connectivity of $\mathbf{1 0}$ is identical to that of $\mathbf{8}$ and $\mathbf{2}$ except for the linkage of the methoxy group to C-9. The relative configuration of $\mathbf{1 0}$ was assigned to match that of $\mathbf{8}$ by analysis of NOESY data including correlations of H-2 with H-3b, H-6, and H-9; of H-6 with $\mathrm{H}-9$; of $\mathrm{H}-3 \mathrm{a}$ with $\mathrm{H}-12 \mathrm{a}$; and of $\mathrm{H}-12 \mathrm{~b}$ with $\mathrm{H}_{3}-15$. Also, as was the case for $\mathbf{8}$, the 
specific rotation value for $\mathbf{1 0}$ was positive, in contrast to the negative value observed for 2. The absolute configuration was presumed to be analogous to that of $\mathbf{8}$ (Deyrup et al., 2006). The name punctaporonin $\mathrm{O}$ was proposed for compound $\mathbf{1 0 .}$

Compound 11 gave the molecular formula $\mathrm{C}_{16} \mathrm{H}_{24} \mathrm{O}_{4}$ by HRESIMS analysis. The ${ }^{1} \mathrm{H}$ NMR data for $\mathbf{1 1}$ showed close resemblance to the set of signals corresponding to the minor solution conformer of 4 . Replacement of one oxygenated methine unit in structure 4 with a ketone group was suggested by changes in the ${ }^{1} \mathrm{H}$ and ${ }^{13} \mathrm{C}$ NMR spectra (Tables 1 and 2). Analysis of HSQC and HMBC data, including HMBC correlations from $\mathrm{H}-2$ and $\mathrm{H}_{2}-7$ to ketone carbon C-6, indicated that 11 differs from 4 by oxidation of the C-6 secondary alcohol group to a ketone unit. The relative configuration of 11, including $E$ geometry for both olefin units, was found to be analogous to that of $\mathbf{4}$ by analysis of NOESY data. Interestingly, in spite of the similarity to $\mathbf{4}$, the ${ }^{1} \mathrm{H}$ NMR spectrum of $\mathbf{1 1}$ showed only one conformer in solution. NOESY correlations of $\mathrm{H}_{3}-15$ with $\mathrm{H}-2, \mathrm{H}-7 \mathrm{~b}$, and $\mathrm{H}-10$ were consistent with adoption of a conformation most closely resembling the minor conformer of 4 (Pulici et al., 1996; Smetanina et al., 2004). A recently published enantioselective total synthesis of pestalotiopsin A (Takao et al., 2009) enabled presumption of the absolute configuration of related compound 4 (Pulici et al., 1996; Smetanina et al., 2004). The absolute configuration of $\mathbf{1 1}$ is presumed to be analogous to that of 4. The 6-O-acetyl-10-hydroxy analogue of fuscoatrol A has been named punctaporonin I (Wu et al., 2014). Therefore, the name punctaporonin $\mathrm{P}$ is suggested here for $\mathbf{1 1}$. Neither $\mathbf{1 0}$ nor $\mathbf{1 1}$ were exposed to methanol during the isolation process, and are therefore considered unlikely to be artifacts arising from the process. 
Compounds 5 - 11 were tested for antifungal activity against Aspergillus flavus and Fusarium verticillioides, but did not account for the activity originally observed for the ethyl acetate extract. Compounds $\mathbf{1}$ and $\mathbf{3}$ are known to show antibacterial activity against Staphylococcus aureus and Bacillus subtilis (Deyrup et al., 2006), and 1 was a major constituent of the extract, however, compounds $\mathbf{5}$ - $\mathbf{1 1}$ were inactive in disk assays (Bauer et al., 1966; Wagenaar et al., 2001) towards S. aureus, B. subtilis, Escherichia coli, and Candida albicans at $100 \mu \mathrm{g} / \mathrm{disk}$.

\section{Experimental}

\subsection{General experimental procedures.}

Optical rotations were measured on an AUTOPOL ${ }^{\circledR} \mathrm{III}$ automatic polarimeter (Rudolph Research Analytical, Hackettstown, NJ). UV data were obtained using $\mathrm{MeOH}$ solutions with a Varian Cary III UV/vis spectrophotometer. HPLC separations were carried out using a Beckman System Gold instrument with a model 166P variablewavelength UV detector connected to a 128 solvent module, equipped with either a preparative Dynamax C18 column (Rainin, $2.0 \times 30 \mathrm{~cm}, 8 \mu \mathrm{m}$ ) or semi-preparative Apollo C18 column (Alltech, $1.5 \times 25 \mathrm{~cm}, 5 \mu \mathrm{m}$ ) under UV detection at $210 \mathrm{~nm} .{ }^{1} \mathrm{H}$ NMR data measurements were conducted using Bruker AVANCE-400 or AVANCE-600 spectrometers. ${ }^{13} \mathrm{C}(150 \mathrm{MHz})$ and $2 \mathrm{D}$ (COSY, HSQC, HMBC, NOESY) NMR spectra

were recorded on the Bruker AVANCE-600 spectrometer. ${ }^{13} \mathrm{C}$ NMR multiplicities were not directly measured, but all assignments are fully consistent with HMQC data. All NMR experiments were performed at $294 \mathrm{~K}$, using $\mathrm{CDCl}_{3}$ or methanol- $d_{4}$ as the solvent. Chemical shifts were referenced to residual solvent signals for $\mathrm{CDCl}_{3}\left(\delta_{\mathrm{H}} / \delta_{\mathrm{C}}, 7.26 / 77.2\right)$ 
or methanol- $d_{4}\left(\delta_{\mathrm{H}} / \delta_{\mathrm{C}}, 3.31 / 49.0\right)$. NMR data processing was carried out with MestReNova v6.0.2 software. HRESITOFMS data were obtained on a Waters Q-ToF Premier mass spectrometer.

\subsection{Fungal culture and extract}

Pestalotiopsis sp. MYC-709 was isolated from a basidioma of Stereum complicatum found on a dead hardwood branch in FDR State Park, Warm Springs, Georgia, USA. After chemical investigation as described below, efforts to identify this organism to species and deposit a subculture in the NRRL culture collection led to the realization that the stored cultures were no longer viable. However, analysis of extract fractions from another, already-deposited Pestalotiopsis culture in our laboratory from which punctaporonin analogues $\mathbf{1}-\mathbf{3}$ had originally been isolated ( $P$. disseminata NRRL 36915; Genbank deposition number GU183121.1; Deyrup et al., 2006; Hwang et al., 2015) revealed the presence of at least four of the same new analogues $(6-9)$. NRRL 36915 also originated as a fungicolous isolate from Georgia, although from a different host and from a site 150 miles to the southeast (from stromata of an unidentified pyrenomycete growing on a dead hardwood branch in Reed Bingham State Park, Adel, GA). This result indicated that Pestalotiopsis sp. MYC-709 was likely to be $P$. disseminata, although this could not be definitively established. Thus, while the procedure described below was that used for the MYC-709 extract, the compounds above were also produced by cultivation of the $P$. disseminata NRRL 36915 culture deposited at the USDA NCAUR. Fermentation and extraction processes leading to production of the extract described below have been reported previously (Hwang et al., 2015). 


\subsection{Isolation}

The EtOAc extract $(687 \mathrm{mg}$ ) obtained from solid-substrate fermentation on rice was partitioned between hexane $(3 \times 8 \mathrm{~mL})$ and $\mathrm{MeCN}(8 \mathrm{~mL})$. The $\mathrm{MeCN}-$ soluble portion $(388 \mathrm{mg})$ was subjected to silica gel column chromatography $(3.2 \times 16 \mathrm{~cm})$ eluting with a stepwise gradient of hexane/EtOAc (200 mL each of 1:0, 9:1, 8:2, 7:3, 6:4, 5:5, 4:6, 3:7, 2:8, 1:9, 0:1), followed by pure $\mathrm{MeOH}(300 \mathrm{~mL})$ resulting in nine combined fractions based on TLC data (Fr. 1 - 9). A portion of Fr. 7 (98 mg out of $143 \mathrm{mg}$ ) was applied to $\mathrm{C}_{18} \mathrm{HPLC}(2.0 \times 30 \mathrm{~cm}, 8 \mathrm{~mL} / \mathrm{min})$ using $18 \% \mathrm{MeCN} / \mathrm{H}_{2} \mathrm{O}$ for $40 \mathrm{~min}$ to yield major components $1\left(15 \mathrm{mg}, t_{\mathrm{R}}=25.2 \mathrm{~min}\right)$ and $2\left(29 \mathrm{mg}, t_{\mathrm{R}}=35.2 \mathrm{~min}\right)$. Fr. $9(157 \mathrm{mg})$ was fractionated over $\mathrm{C}_{18} \mathrm{HPLC}(2.0 \times 30 \mathrm{~cm}, 8 \mathrm{~mL} / \mathrm{min})$ with $15 \% \mathrm{MeCN} / \mathrm{H}_{2} \mathrm{O}$ over 30 min to obtain $5\left(\right.$ Fr. 9-3; $\left.2.0 \mathrm{mg}, t_{\mathrm{R}}=14.1 \mathrm{~min}\right), 6\left(\right.$ Fr. 9-5; $\left.2.4 \mathrm{mg}, t_{\mathrm{R}}=27.5 \mathrm{~min}\right)$, and four other subfractions (Fr. 9-1, 9-2, 9-4, and 9-6). Fr. 9-2 (3.9 mg) was purified by $\mathrm{C}_{18}$ HPLC $(1.0 \times 25 \mathrm{~cm}, 1.5 \mathrm{~mL} / \mathrm{min})$ with $12 \% \mathrm{MeCN} / \mathrm{H}_{2} \mathrm{O}$ for $20 \mathrm{~min}$ to afford $7(0.7 \mathrm{mg}$, $\left.t_{\mathrm{R}}=16.0 \mathrm{~min}\right)$. Fr. $8(29 \mathrm{mg})$ was chromatographed over $\mathrm{C}_{18} \operatorname{HPLC}(2.0 \times 30 \mathrm{~cm}, 8$ $\mathrm{mL} / \mathrm{min}$ ) using $18 \% \mathrm{MeCN} / \mathrm{H}_{2} \mathrm{O}$ for $40 \mathrm{~min}$, followed by a linear increase of $\mathrm{MeCN} / \mathrm{H}_{2} \mathrm{O}$ from $18 \%$ to $60 \%$ over $20 \mathrm{~min}$ to give $\mathbf{8}\left(3.0 \mathrm{mg}, t_{\mathrm{R}}=39.1 \mathrm{~min}\right)$ and $\mathbf{3}\left(6.7 \mathrm{mg}, t_{\mathrm{R}}=51.9\right.$ min). Fr. $6(26 \mathrm{mg})$ was subjected to $\mathrm{C}_{18} \operatorname{HPLC}(1.0 \times 25 \mathrm{~cm}, 2 \mathrm{~mL} / \mathrm{min})$ with $28 \%$ $\mathrm{MeCN} / \mathrm{H}_{2} \mathrm{O}$ for $20 \mathrm{~min}$, then a linear gradient of $\mathrm{MeCN} / \mathrm{H}_{2} \mathrm{O}$ from $28 \%$ to $50 \%$ over 45 min to yield $9\left(1.1 \mathrm{mg}, t_{\mathrm{R}}=15.7 \mathrm{~min}\right)$ and $\mathbf{1 0}\left(1.7 \mathrm{mg}, t_{\mathrm{R}}=37.0 \mathrm{~min}\right)$. Compounds $4(7.8$ $\left.\mathrm{mg}, t_{\mathrm{R}}=32.1 \mathrm{~min}\right)$ and $11\left(1.4 \mathrm{mg}, t_{\mathrm{R}}=33.3 \mathrm{~min}\right)$ were isolated from Fr. $5(28 \mathrm{mg})$ by $\mathrm{C}_{18} \mathrm{HPLC}(1.0 \times 25 \mathrm{~cm}, 2 \mathrm{~mL} / \mathrm{min})$ eluting with $30 \% \mathrm{MeCN} / \mathrm{H}_{2} \mathrm{O}$ for $15 \mathrm{~min}$, followed by a linear increase to $60 \% \mathrm{MeCN}$ over 45 min. Known compounds $\mathbf{1}-\mathbf{4}$ were identified 
by comparison of their NMR and $[\alpha]_{D}$ data to literature values (Deyrup et al., 2006;

Smetanina et al., 2004).

\subsubsection{6,13-Dihydroxypunctaporonin A (5)}

Colorless glass; $[\alpha]^{22}-11(c 0.11, \mathrm{MeOH}) ;{ }^{1} \mathrm{H}$ NMR data, see Table $1 ;{ }^{13} \mathrm{C}$ NMR data, see Table 2; HMBC data: H-2 $\rightarrow$ C-1, 3, 4, 5, 6, 11, 12; H-3a $\rightarrow$ C-1, 2, 4, 5, 13; H$3 b \rightarrow \mathrm{C}-2,4,5,6^{*}, 13 ; \mathrm{H}-6 \rightarrow \mathrm{C}-5,7 ; \mathrm{H}-7 \mathrm{a} \rightarrow \mathrm{C}-1,5,6,8,9 ; \mathrm{H}-7 \mathrm{~b} \rightarrow \mathrm{C}-5,6,8,9,15 ;$ $\mathrm{H}-9 \rightarrow 1,10,11,15 ; \mathrm{H}-10$ or $11 \rightarrow \mathrm{C}-1,2,8,9,10,11,12 ; \mathrm{H}-12 \mathrm{a} \rightarrow \mathrm{C}-1,2,8,11 ; \mathrm{H}-$ $12 \mathrm{~b} \rightarrow \mathrm{C}-1,2,8,11 ; \mathrm{H}_{2}-13 \rightarrow \mathrm{C}-3,4,5,14 ; \mathrm{H}_{3}-14 \rightarrow \mathrm{C}-3,4,5,13 ; \mathrm{H}_{3}-15 \rightarrow \mathrm{C}-1,6^{*}, 7$, 8, 9; *Four-bond correlation; NOESY data: H-2 $\leftrightarrow \mathrm{H}-3 \mathrm{~b}, 6,13 ; \mathrm{H}-3 \mathrm{a} \leftrightarrow \mathrm{H}-12 \mathrm{a}, 14 ; \mathrm{H}-3 \mathrm{~b}$ $\leftrightarrow \mathrm{H}-2,13 ; \mathrm{H}-6 \leftrightarrow \mathrm{H}-2,7 \mathrm{a}, 13 ; \mathrm{H}-7 \mathrm{a} \leftrightarrow \mathrm{H}-6,9 ; \mathrm{H}-7 \mathrm{~b} \leftrightarrow \mathrm{H}-15 ; \mathrm{H}-9 \leftrightarrow \mathrm{H}-7 \mathrm{a}, 15 ; \mathrm{H}-12 \mathrm{a}$ $\leftrightarrow \mathrm{H}-3 \mathrm{a} ; \mathrm{H}-12 \mathrm{~b} \leftrightarrow \mathrm{H}-15 ; \mathrm{H}_{2}-13 \leftrightarrow \mathrm{H}-2,3 \mathrm{~b}, 6,14 ; \mathrm{H}_{3}-14 \leftrightarrow \mathrm{H}-3 \mathrm{a}, 13 ; \mathrm{H}_{3}-15 \leftrightarrow \mathrm{H}-7 \mathrm{~b}, 9$ 12b; HRESIMS $m / z$ 283.1542 [M - H] $]^{-}$(calcd for $\mathrm{C}_{15} \mathrm{H}_{23} \mathrm{O}_{5}, 283.1545$ ).

\subsubsection{6,13-Dihydroxypunctaporonin B (6)}

Colorless glass; $[\alpha]_{\mathrm{D}}^{22}-80(c 0.12, \mathrm{MeOH}) ;{ }^{1} \mathrm{H}$ NMR data, see Table $1 ;{ }^{13} \mathrm{C}$ NMR data, see Table 2; HMBC data: $\mathrm{H}-2 \rightarrow \mathrm{C}-1,3,5,6,11,12 ; \mathrm{H}-3 \mathrm{a} \rightarrow \mathrm{C}-1,2,4,13,14 ; \mathrm{H}-$ $3 \mathrm{~b} \rightarrow \mathrm{C}-2,4,5,13 ; \mathrm{H}-6 \rightarrow \mathrm{C}-7,8 ; \mathrm{H}-7 \mathrm{a} \rightarrow \mathrm{C}-5,6 ; \mathrm{H}-7 \mathrm{~b} \rightarrow \mathrm{C}-6,9 ; \mathrm{H}-9 \rightarrow 7,11 ; \mathrm{H}-10$ $\rightarrow \mathrm{C}-1,8 ; \mathrm{H}-11 \rightarrow \mathrm{C}-1,2,9,12 ; \mathrm{H}-12 \mathrm{a} \rightarrow \mathrm{C}-1,11 ; \mathrm{H}-12 \mathrm{~b} \rightarrow \mathrm{C}-1,2,11 ; \mathrm{H}-13 \mathrm{a} \rightarrow \mathrm{C}-3,4$ 5, 14; H-13b $\rightarrow$ C-3, 4, 5, 14; $\mathrm{H}_{3}-14 \rightarrow \mathrm{C}-3,4,5,13 ; \mathrm{H}_{3}-15 \rightarrow \mathrm{C}-7,8,9$; NOESY data: H-2 $\leftrightarrow$ H-3b, 6, 7a, 9, 10, 11, 13a; H-3a ↔ H-12a, 12b, 14; H-3b $\leftrightarrow$ H-2, 13a, 13b; H-6 $\leftrightarrow \mathrm{H}-2,7 \mathrm{a}, 7 \mathrm{~b}, 9,13 \mathrm{~b} ; \mathrm{H}-7 \mathrm{a} \leftrightarrow \mathrm{H}-2,6,11,15 ; \mathrm{H}-7 \mathrm{~b} \leftrightarrow \mathrm{H}-6,15 ; \mathrm{H}-9 \leftrightarrow \mathrm{H}-2,6,15 ; \mathrm{H}-10$ 
$\leftrightarrow \mathrm{H}-2 ; \mathrm{H}-11 \leftrightarrow \mathrm{H}-2,7 \mathrm{a}, 12 \mathrm{~b}, 15 ; \mathrm{H}-12 \mathrm{a} \leftrightarrow \mathrm{H}-3 \mathrm{a} ; \mathrm{H}-12 \mathrm{~b} \leftrightarrow \mathrm{H}-3 \mathrm{a}, 11 ; \mathrm{H}-13 \mathrm{a} \leftrightarrow \mathrm{H}-2,3 \mathrm{~b}$

$\mathrm{H}-13 \mathrm{~b} \leftrightarrow \mathrm{H}-3 \mathrm{~b}, 6,14 ; \mathrm{H}_{3}-14 \leftrightarrow \mathrm{H}-3 \mathrm{a}, 13 \mathrm{~b} ; \mathrm{H}_{3}-15 \leftrightarrow \mathrm{H}-7 \mathrm{a}, 7 \mathrm{~b}, 9,11$; HRESIMS $m / z$ $283.1541[\mathrm{M}-\mathrm{H}]^{-}$(calcd for $\left.\mathrm{C}_{15} \mathrm{H}_{23} \mathrm{O}_{5}, 283.1545\right)$.

\subsubsection{6,13-Dihydroxypunctaporonin E (7)}

Colorless glass; $[\alpha]{ }^{22}{ }_{\mathrm{D}}-48(c$ 0.06, MeOH $) ;{ }^{1} \mathrm{H}$ NMR data, see Table $1 ;{ }^{13} \mathrm{C}$ NMR data, see Table 2; HMBC data: $\mathrm{H}-2 \rightarrow \mathrm{C}-1,3,6,11,12 ; \mathrm{H}-3 \mathrm{a} \rightarrow \mathrm{C}-2,4,13,14 ; \mathrm{H}-3 \mathrm{~b} \rightarrow$ $\mathrm{C}-2,4,5,13 ; \mathrm{H}-6 \rightarrow \mathrm{C}-5,7 ; \mathrm{H}-7 \mathrm{a} \rightarrow \mathrm{C}-6,8,9,15 ; \mathrm{H}-7 \mathrm{~b} \rightarrow \mathrm{C}-1,5,6,8,9 ; \mathrm{H}-9 \rightarrow 1,7,8$, 10,$11 ; \mathrm{H}-10 \rightarrow \mathrm{C}-1,8,9,11 ; \mathrm{H}-11 \rightarrow \mathrm{C}-2,8,9,10 ; \mathrm{H}-12 \mathrm{a} \rightarrow \mathrm{C}-1,2,11 ; \mathrm{H}-12 \mathrm{~b} \rightarrow \mathrm{C}-2$, $8 ; \mathrm{H}_{2}-13 \rightarrow \mathrm{C}-3,4,5,14 ; \mathrm{H}_{3}-14 \rightarrow \mathrm{C}-3,4,5,13 ; \mathrm{H}_{3}-15 \rightarrow \mathrm{C}-1,7,8$, 9; NOESY data: H$2 \leftrightarrow \mathrm{H}-3 \mathrm{~b}, 6,9,10,11,13 ; \mathrm{H}-3 \mathrm{a} \leftrightarrow \mathrm{H}-12 \mathrm{~b}, 14 ; \mathrm{H}-3 \mathrm{~b} \leftrightarrow \mathrm{H}-2,11 ; \mathrm{H}-6 \leftrightarrow \mathrm{H}-2,7 \mathrm{~b}, 9,13 \mathrm{a} ;$ H-7b $\leftrightarrow \mathrm{H}-6,9 ; \mathrm{H}-9 \leftrightarrow \mathrm{H}-2,6,7 \mathrm{~b}, 10,15 ; \mathrm{H}-10 \leftrightarrow \mathrm{H}-2,9 ; \mathrm{H}-11 \leftrightarrow \mathrm{H}-2,3 \mathrm{~b} ; \mathrm{H}-12 \mathrm{a} \leftrightarrow$ 15; H-12b $\leftrightarrow \mathrm{H}-3 \mathrm{a} ; \mathrm{H}_{2}-13 \leftrightarrow \mathrm{H}-2,6 ; \mathrm{H}_{3}-14 \leftrightarrow \mathrm{H}-3 \mathrm{a} ; \mathrm{H}_{3}-15 \leftrightarrow \mathrm{H}-9,12 \mathrm{a}$; HRESIMS $m / z$ $283.1533[\mathrm{M}-\mathrm{H}]^{-}$(calcd for $\mathrm{C}_{15} \mathrm{H}_{23} \mathrm{O}_{5}, 283.1545$ ).

\subsubsection{6-Hydroxypunctaporonin $D(8)$}

White amorphous solid; $[\alpha]^{22}+104(c 0.15, \mathrm{MeOH}) ;{ }^{1} \mathrm{H}$ NMR data, see Table 1;

${ }^{13} \mathrm{C}$ NMR data, see Table 2; HMBC data: $\mathrm{H}-2 \rightarrow \mathrm{C}-1,3,5,6,11,12 ; \mathrm{H}-3 \mathrm{a} \rightarrow \mathrm{C}-2,4,13$; $\mathrm{H}-3 \mathrm{~b} \rightarrow \mathrm{C}-1,2,4,5,6^{*}, 12^{*}, 13 ; \mathrm{H}-6 \rightarrow \mathrm{C}-5,7 ; \mathrm{H}-7 \mathrm{a} \rightarrow \mathrm{C}-1,5,6,8,9 ; \mathrm{H}-7 \mathrm{~b} \rightarrow \mathrm{C}-5,6,8$, 9, 15; H-9 $\rightarrow$ C-1, 2* $7,10,11,12^{*}, 15 ; \mathrm{H}-10 \rightarrow \mathrm{C}-1,8,9,11 ; \mathrm{H}-11 \rightarrow \mathrm{C}-1,2,8,9,10$, $12 ; \mathrm{H}-12 \mathrm{a} \rightarrow \mathrm{C}-1,2,8,11 ; \mathrm{H}-12 \mathrm{~b} \rightarrow \mathrm{C}-1,2,8,11 ; \mathrm{H}_{3}-13 \rightarrow \mathrm{C}-3,4,5,14 ; \mathrm{H}_{3}-14 \rightarrow \mathrm{C}-3$, 
4, 5, 13; $\mathrm{H}_{3}-15 \rightarrow \mathrm{C}-1,6^{*}, 7,8,9 ;{ }^{*}$ Four-bond correlation; NOESY data: $\mathrm{H}-2 \leftrightarrow \mathrm{H}-3 \mathrm{~b}, 6$, 9, 13; H-3a $\leftrightarrow$ H-12a, 14; H-3b $\leftrightarrow$ H-2, 13; H-6 $\leftrightarrow$ H-2, 7a, 9, 13; H-7a $\leftrightarrow$ H-6, 9, 15; H$7 \mathrm{~b} \leftrightarrow \mathrm{H}-6,15 ; \mathrm{H}-9 \leftrightarrow \mathrm{H}-2,6,7 \mathrm{a} ; \mathrm{H}-12 \mathrm{a} \leftrightarrow \mathrm{H}-3 \mathrm{a} ; \mathrm{H}-12 \mathrm{~b} \leftrightarrow \mathrm{H}-15 ; \mathrm{H}_{3}-13 \leftrightarrow \mathrm{H}-2,3 \mathrm{~b}, 6$ $\mathrm{H}_{3}-14 \leftrightarrow \mathrm{H}-3 \mathrm{a} ; \mathrm{H}_{3}-15 \leftrightarrow \mathrm{H}-7 \mathrm{a}, 7 \mathrm{~b}, 12 \mathrm{~b}$; HRESIMS $m / z 267.1590[\mathrm{M}-\mathrm{H}]^{-}$(calcd for $\left.\mathrm{C}_{15} \mathrm{H}_{23} \mathrm{O}_{4}, 267.1596\right)$.

\subsubsection{Punctaporonin N(9)}

White amorphous solid; $[\alpha]_{\mathrm{D}}^{22}+18(c 0.10, \mathrm{MeOH}) ; \mathrm{UV}(\mathrm{MeOH}) \lambda_{\max } 232 \mathrm{~nm}$ $\left(\log \varepsilon\right.$ 3.35); ${ }^{1} \mathrm{H}$ NMR data, see Table $1 ;{ }^{13} \mathrm{C}$ NMR data, see Table 2; HMBC data: $\mathrm{H}-2 \rightarrow$ $\mathrm{C}-1,3,4,5,6,11,12 ; \mathrm{H}-3 \mathrm{a} \rightarrow \mathrm{C}-1,2,4,14 ; \mathrm{H}-3 \mathrm{~b} \rightarrow \mathrm{C}-2,4,5,6^{*}, 14 ; \mathrm{H}-6 \rightarrow \mathrm{C}-5,7 ; \mathrm{H}-$ $7 \mathrm{a} \rightarrow \mathrm{C}-1,5,6,8,9 ; \mathrm{H}-7 \mathrm{~b} \rightarrow \mathrm{C}-6,8,9,15 ; \mathrm{H}-10 \rightarrow \mathrm{C}-1,2^{*}, 8,9,11 ; \mathrm{H}-11 \rightarrow \mathrm{C}-1,2,8$, $9,10,12 ; \mathrm{H}-12 \mathrm{a} \rightarrow \mathrm{C}-1,2,8,11 ; \mathrm{H}-12 \mathrm{~b} \rightarrow \mathrm{C}-1,2,8,11 ; \mathrm{H}_{3}-13 \rightarrow \mathrm{C}-3,4,5,14 ; \mathrm{H}_{3}-14$

$\rightarrow \mathrm{C}-3,4,5,13 ; \mathrm{H}_{3}-15 \rightarrow \mathrm{C}-1,6^{*}, 7,8,9 ;{ }^{*}$ Four-bond correlation; HRESIMS $\mathrm{m} / z$ 265.1448 [M-H] ${ }^{-}$(calcd for $\mathrm{C}_{15} \mathrm{H}_{21} \mathrm{O}_{4}, 265.1440$ ).

\subsubsection{Punctaporonin $O(\mathbf{1 0})$}

White amorphous solid; $[\alpha]^{22}+42(c 0.14, \mathrm{MeOH}) ;{ }^{1} \mathrm{H}$ NMR data, see Table 1;

${ }^{13} \mathrm{C}$ NMR data, see Table 2; HMBC data: $\mathrm{H}-2 \rightarrow \mathrm{C}-3,4,5,6,11,12 ; \mathrm{H}-3 \mathrm{a} \rightarrow \mathrm{C}-1,2,4$, 13,$14 ; \mathrm{H}-3 \mathrm{~b} \rightarrow \mathrm{C}-2,4,5,6^{*}, 13,14 ; \mathrm{H}-6 \rightarrow \mathrm{C}-5,7 ; \mathrm{H}-7 \mathrm{a} \rightarrow \mathrm{C}-1,5,6,9 ; \mathrm{H}-7 \mathrm{~b} \rightarrow \mathrm{C}-6,8$, 9, 15; H-9 $\rightarrow$ C-7, 10, 11, 15, $\mathrm{OCH}_{3} ; \mathrm{H}-10 \rightarrow \mathrm{C}-1,2^{*}, 8,9,11 ; \mathrm{H}-11 \rightarrow \mathrm{C}-1,8,9,10,12$; $\mathrm{H}-12 \mathrm{a} \rightarrow \mathrm{C}-2,8,11 ; \mathrm{H}-12 \mathrm{~b} \rightarrow \mathrm{C}-1,2,11 ; \mathrm{H}_{3}-13 \rightarrow \mathrm{C}-3,4,5,14 ; \mathrm{H}_{3}-14 \rightarrow \mathrm{C}-3,4,5,13 ;$ $\mathrm{H}_{3}-15 \rightarrow \mathrm{C}-1,6^{*}, 7,8,9 ; \mathrm{OCH}_{3} \rightarrow \mathrm{C}-9$; "Four-bond correlation; NOESY data: $\mathrm{H}-2 \leftrightarrow \mathrm{H}-$ 3b, 6, 9, 10, 11, 13; H-3a ↔ H-12a, 14; H-3b H-2, 11, 13; H-6 ↔ H-2, 7a, 9, 13; H-7a 
$\leftrightarrow \mathrm{H}-6,9 ; \mathrm{H}-7 \mathrm{~b} \leftrightarrow \mathrm{H}-15 ; \mathrm{H}-9 \leftrightarrow \mathrm{H}-2,6,7 \mathrm{a}, 10 ; \mathrm{H}-10 \leftrightarrow \mathrm{H}-2,9 ; \mathrm{H}-11 \leftrightarrow \mathrm{H}-2,3 \mathrm{~b}, 12 \mathrm{a}$,

12b; H-12a $\leftrightarrow \mathrm{H}-3 \mathrm{a}, 11 ; \mathrm{H}-12 \mathrm{~b} \leftrightarrow \mathrm{H}-11,15 ; \mathrm{H}_{3}-13 \leftrightarrow \mathrm{H}-2,3 \mathrm{~b}, 6 ; \mathrm{H}_{3}-14 \leftrightarrow \mathrm{H}-3 \mathrm{a} ; \mathrm{H}_{3}-15$

$\leftrightarrow \mathrm{H}-7 \mathrm{~b}, 12 \mathrm{~b} ; \mathrm{OCH}_{3} \leftrightarrow \mathrm{H}-9,10 ;$ HRESIMS $m / z, 281.1744[\mathrm{M}-\mathrm{H}]^{-}$(calcd for $\mathrm{C}_{16} \mathrm{H}_{25} \mathrm{O}_{4}$, 281.1753).

\subsubsection{Punctaporonin $P(11)$}

Colorless glass; $[\alpha]^{22}{ }_{\mathrm{D}}-52(c 0.06, \mathrm{MeOH}) ;{ }^{1} \mathrm{H}$ NMR data, see Table $1 ;{ }^{13} \mathrm{C}$ NMR data, see Table 2; HMBC data: H-2 $\rightarrow$ C-1, 3, 5, 6, 11, 12; H-3a $\rightarrow$ C-1, 2, 4, 13, 14; H$3 \mathrm{~b} \rightarrow \mathrm{C}-2,4,5,6^{*}, 13 ; \mathrm{H}-7 \mathrm{a} \rightarrow \mathrm{C}-5,6,8,9 ; \mathrm{H}-7 \mathrm{~b} \rightarrow \mathrm{C}-5,6,8,9,10^{*}, 15 ; \mathrm{H}-9 \rightarrow 7,11$, $15 ; \mathrm{H}-10 \rightarrow \mathrm{C}-1,8,9,11, \mathrm{OCH}_{3} ; \mathrm{H}-11 \rightarrow \mathrm{C}-1,2,5^{*}, 9,12 ; \mathrm{H}-12 \mathrm{a} \rightarrow \mathrm{C}-1,2,11 ; \mathrm{H}-12 \mathrm{~b}$ $\rightarrow \mathrm{C}-1,2,11 ; \mathrm{H}_{3}-13 \rightarrow \mathrm{C}-3,4,5,14 ; \mathrm{H}_{3}-14 \rightarrow \mathrm{C}-3,4,5,13 ; \mathrm{H}_{3}-15 \rightarrow \mathrm{C}-7,8,9 ; \mathrm{OCH}_{3}$ $\rightarrow \mathrm{C}-10$; ${ }^{*}$ Four-bond correlation; NOESY data: H-2 $\leftrightarrow \mathrm{H}-3 \mathrm{~b}, 10,11,13,15 ; \mathrm{H}-3 \mathrm{a} \leftrightarrow \mathrm{H}-$ 12a, 14; H-3b $\leftrightarrow$ H-2, 13; H-7a $\leftrightarrow \mathrm{H}-9 ; \mathrm{H}-7 \mathrm{~b} \leftrightarrow \mathrm{H}-13,15 ; \mathrm{H}-9 \leftrightarrow \mathrm{H}-7 \mathrm{a}, 10,11,16 ; \mathrm{H}-10$ $\leftrightarrow \mathrm{H}-2,9,11,15,16 ; \mathrm{H}-11 \leftrightarrow \mathrm{H}-2,9,10,12 \mathrm{~b}, 16 ; \mathrm{H}-12 \mathrm{a} \leftrightarrow \mathrm{H}-3 \mathrm{a} ; \mathrm{H}-12 \mathrm{~b} \leftrightarrow \mathrm{H}-11 ; \mathrm{H}_{3}-$ $13 \leftrightarrow \mathrm{H}-2,3 b, 7 b ; \mathrm{H}_{3}-14 \leftrightarrow \mathrm{H}-3 \mathrm{a} ; \mathrm{H}_{3}-15 \leftrightarrow \mathrm{H}-2,7 \mathrm{~b}, 10 ; \mathrm{OCH}_{3} \leftrightarrow \mathrm{H}-9,10,11$

HRESIMS $m / z 303.1563[\mathrm{M}+\mathrm{Na}]^{+}\left(\right.$calcd for $\mathrm{C}_{16} \mathrm{H}_{24} \mathrm{O}_{4} \mathrm{Na}, 303.1572$ ), $583.3242[2 \mathrm{M}+$ $\mathrm{Na}]^{+}$(calcd for $\mathrm{C}_{32} \mathrm{H}_{48} \mathrm{O}_{8} \mathrm{Na}$, 583.3247).

\subsection{Oxidation of 6-hydroxypunctaporonin A.}

A sample of 6-hydroxypunctaporonin A $(2 ; 5.0 \mathrm{mg})$ was dissolved in dry acetone $(1.6 \mathrm{~mL})$ with excess pyrazole $(2 \%, 32 \mathrm{mg})$, and PCC $(12.1 \mathrm{mg})$ was added to the solution. The reaction was stirred under argon at $2-3^{\circ} \mathrm{C}$ and monitored by TLC using 2,4-dinitrophenylhydrazine staining. After stirring for $4 \mathrm{hr}$, saturated aqueous $\mathrm{NaCl}$ 
solution $(10 \mathrm{~mL})$ was added, and the mixture was extracted with $\mathrm{CHCl}_{3}(3 \times 10 \mathrm{~mL})$.

The organic layer was collected, dried, evaporated, and purified by $\mathrm{C}_{18} \mathrm{HPLC}(2.0 \times 30$ $\mathrm{cm}, 8 \mathrm{~mL} / \mathrm{min}$ ) eluting with $22 \% \mathrm{MeCN} / \mathrm{H}_{2} \mathrm{O}$ for $20 \mathrm{~min}$, followed by a linear increase from $22 \%$ to $50 \% \mathrm{MeCN} / \mathrm{H}_{2} \mathrm{O}$ over $20 \mathrm{~min}$ to obtain a sample of $9\left(0.8 \mathrm{mg}, t_{\mathrm{R}}=24.0\right.$ min), which gave NMR data identical to those of the sample of 9 isolated from the extract.

\section{Acknowledgments}

Financial support was provided in part by a grant from the National Science Foundation (CHE-1011847). Acquisition of the $600 \mathrm{MHz}$ NMR and HRMS instruments employed in this work was supported by grants from NIH (S 10 RR025500) and NSF (CHE-0946779), respectively. Technical assistance from staff of the University of Iowa NMR and MS facilities is greatly appreciated. The USDA is an equal opportunity provider and employer. 


\section{References}

Anderson, J.R., Edwards, R.L., Poyser, J.P., Whalley, A.J., 1988. Metabolites of the higher fungi. Part 23. The punctaporonins. Novel bi-, tri-, and tetra-cyclic sesquiterpenes related to caryophyllene, from the fungus Poronia punctata (Linnaeus: Fries) Fries. J. Chem. Soc., Perkin Trans. I, 823-831.

Bauer, A.W., Kirby, W.M.M., Sherris, J.C., Turck, M., 1966. Antibiotic susceptibility testing by a standardized single disk method. Am. J. Clin. Pathol. 45, 493-496.

Collado, I.G., Hanson, J.R., Macias-Sanchez, A.J., 1998. Recent advances in the chemistry of caryophyllene. Nat. Prod. Rep. 15, 187-204.

Deyrup, S.T., Swenson, D.C., Gloer, J.B., Wicklow, D.T., 2006. Caryophyllene sesquiterpenoids from a fungicolous isolate of Pestalotiopsis disseminata. J. Nat. Prod. $69,608-611$.

Gloer, J. B. 2007. Applications of Fungal Ecology in the Search for New Bioactive Natural Products. In: The Mycota, Volume IV, 2nd Edition; Kubicek, C. P.; Druzhinina, I. S., Eds.; Springer-Verlag: New York, pp. 257-283.

Hwang, I.H., Swenson, D.C., Gloer, J.B., Wicklow, D.T., 2015. Pestaloporonins: caryophyllene-derived sesquiterpenoids from a fungicolous isolate of Pestalotiopsis sp. Org. Lett. 17, 4284-4287.

Li, Y., Li, C.-W., Cui, C.-B., Liu, X.-Z., Che, Y.-S., 2012. Cytosporinols A-C, new caryophyllene sesquiterpenoids from Cytospora sp. Nat. Prod. Bioprospect. 2, 70-75.

Parish, E.J., Chitrakorn, S., Lowery, S., 1984. Selective oxidation of steroidal allylic 
alcohols using pyrazole and pyridinium chlorochoromate. Lipids 19, 550-552.

Poyser, J.P., Edwards, R.L., Anderson, J.R., Hursthouse, M.B., Walker, N.P., Sheldrick, G.M., Whalley, A.J., 1986. Punctaporonins A, D, E, and F (antibiotics M95464, M167906, M171950, and M189122), isomeric allylic alcohols from the fungus Poronia punctata: X-ray crystal structures of D and of E acetonide. J. Antibiot. 39, 167-169.

Pulici, M., Sugawara, F., Koshino, H., Uzawa, J., Yoshida, S.; Lobkovsky, E., Clardy, J., 1996. Pestalotiopsins A and B: new caryophyllenes from an endophytic fungus of Taxus brevifolia. J. Org. Chem. 61, 2122-2124.

Shim, S. H.; Baltrusaitis, J.; Gloer, J. B.; Wicklow, D.T. 2011. Phomalevones A-C: Dimeric and Pseudodimeric Polyketides from a Fungicolous Hawaiian Isolate of Phoma sp. (Cucurbitariaceae). J. Nat. Prod. 72, 395-401.

Smetanina, O.F., Kuznetsova, T.A., Gerasimenko, A.V., Kalinovsky, A.I., Pivkin, M.V., Dmitrenok, P.C., Elyakov, G.B., 2004. Metabolites of the marine fungus Humicola fuscoatra KMM 4629. Russ. Chem. Bull. 53, 2643-2646.

Takao, K., Hayakawa, N., Yamada, R., Yamaguchi, T., Saegusa, H., Uchida, M., Samejima, S., Tadano, K., 2009. Total syntheses of (+)- and (-)-pestalotiopsin A. J. Org. Chem. 74, 6452-6461.

Wagenaar, M.M., Clardy, J., 2001. Dicerandrols, new antibiotic and cytotoxic dimers produced by the fungus Phomopsis longicolla Isolated from an Endangered Mint. J. Nat. Prod. 64, 1006-1009.

Wu, Z., Liu, D., Proksch, P., Guo, P., Lin, W., 2014. Punctaporonins H-M: 
caryophyllene-type sesquiterpenoids from the sponge-associated fungus Hansfordia sinuosae. Mar. Drugs 12, 3904-3916.

Yang, S.-W., Chan, T.-M., Terracciano, J., Boehm, E., Patel, R., Chen, G., Leobenberg, D., Patel, M., Gullo, V., Pramanik, B., Chu, M., 2009. Caryophyllenes from a fungal culture of Chrysosporium pilosum. J. Nat. Prod. 72, 484-487. 


\section{Table 1.}

${ }^{1} \mathrm{H}$ NMR Spectroscopic Data $\left(\delta_{\mathrm{H}}, J\right.$ in $\left.\mathrm{Hz}\right)$ for Compounds 5 - 11

\begin{tabular}{|c|c|c|c|c|c|c|c|}
\hline position & $\mathbf{5}^{a}$ & $6^{a}$ & $7^{a}$ & $8^{a}$ & $\mathbf{9}^{b}$ & $10^{b}$ & $11^{b}$ \\
\hline 2 & 2.38, dd $(13,8.1)$ & 3.36 , dd $(12,8.6)$ & $2.13, \mathrm{dd}(13,7.8)$ & 2.04, dd $(13,5.4)$ & $1.55, \mathrm{dd}(12,7.8)$ & 2.03 , dd $(13,7.2)$ & 3.72, dd $(11,9.1)$ \\
\hline $3 a$ & 1.95 , dd $(13,9.6)$ & $2.08, \mathrm{dd}(12,11)$ & 1.99, dd $(13,9.6)$ & 2.08, dd $(13,6.0)$ & $2.17, \mathrm{dd}(12,9.0)$ & 2.09, dd $(13,8.4)$ & $2.35, \mathrm{dd}(11,11)$ \\
\hline $3 b$ & $1.77, \mathrm{dd}(9.6,8.1)$ & 1.56, dd $(11,8.6)$ & $1.80, \mathrm{dd}(9.6,7.8)$ & $1.48, \mathrm{dd}(6.0,5.4)$ & $1.61, \mathrm{dd}(9.0,7.8)$ & $1.52, \mathrm{dd}(8.4,7.2)$ & 1.65 , dd $(11,9.1)$ \\
\hline 6 & $4.11, \mathrm{dd}(10,5.4)$ & $4.03, \mathrm{dd}(4.3,2.0)$ & $3.51, \mathrm{dd}(11,4.8)$ & 3.93 , dd $(11,5.1)$ & 3.64 , dd $(11,5.4)$ & 3.99, dd $(11,4.8)$ & \\
\hline $7 \mathrm{a}$ & $1.89, \mathrm{dd}(14,5.4)$ & 2.72, dd $(16,4.3)$ & $1.83, \mathrm{dd}(13,11)$ & 1.91, dd $(13,5.1)$ & $2.41, \mathrm{dd}(14,5.4)$ & $2.02, \mathrm{dd}(14,4.8)$ & 3.68, ddd $(19,1.7,1.5)$ \\
\hline $7 b$ & 1.67, dd $(14,10)$ & $1.43, \operatorname{ddd}(16,2.0,2.0)$ & $1.72, \mathrm{dd}(13,4.8)$ & $1.63, \mathrm{dd}(13,11)$ & $1.68, \mathrm{dd}(14,11)$ & $1.64, \mathrm{dd}(14,11)$ & $3.00, \mathrm{~d}(19)$ \\
\hline 9 & 4.07, br s & 5.73, ddd $(13,1.5,1.5)$ & $5.81, \mathrm{~d}(6.0)$ & $4.86, \mathrm{~s}$ & & $4.36, \mathrm{dd}(1.7,1.2)$ & 4.91, dm (10) \\
\hline 10 & $5.71, \mathrm{~s}$ & 5.65, ddd $(13,2.4,2.3)$ & $5.63, \mathrm{dd}(6.0,2.7)$ & $5.55, \mathrm{~d}(6.6)$ & $6.00, \mathrm{~d}(6.0)$ & $5.71, \mathrm{dd}(6.1,1.2)$ & 4.61, br d (10) \\
\hline 11 & $5.71, \mathrm{~s}$ & 5.87, br s & $4.07, \mathrm{~d}(2.7)$ & $5.54, \mathrm{~d}(6.6)$ & $7.37, \mathrm{~d}(6.0)$ & 5.53, dd $(6.1,1.7)$ & $5.86, \mathrm{~s}$ \\
\hline $12 \mathrm{a}$ & $3.70, \mathrm{~d}(11)$ & 4.19, ddd $(12,1.7,1.6)$ & $4.06, \mathrm{~d}(11)$ & $3.67, \mathrm{~d}(11)$ & $3.85, \mathrm{~d}(11)$ & $3.70, \mathrm{~d}(11)$ & $4.04, \mathrm{~d}(11)$ \\
\hline $12 \mathrm{~b}$ & $3.48, \mathrm{~d}(11)$ & $3.97, \mathrm{~d}(12)$ & $3.69, \mathrm{~d}(11)$ & $3.53, \mathrm{~d}(11)$ & $3.69, \mathrm{~d}(11)$ & $3.57, \mathrm{~d}(11)$ & $3.85, \mathrm{~d}(11)$ \\
\hline $13 \mathrm{a}$ & $3.67, \mathrm{~s}$ & $3.91, \mathrm{~d}(11)$ & $3.62, \mathrm{~d}(11)$ & $1.20, \mathrm{~s}$ & $1.14, \mathrm{~s}$ & $1.21, \mathrm{~s}$ & $1.19, \mathrm{~s}$ \\
\hline $13 b$ & $3.67, \mathrm{~s}$ & $3.54, \mathrm{~d}(11)$ & $3.59, \mathrm{~d}(11)$ & & & & \\
\hline 14 & $1.18, \mathrm{~s}$ & $1.19, \mathrm{~s}$ & $1.18, \mathrm{~s}$ & $1.13, \mathrm{~s}$ & $1.10, \mathrm{~s}$ & $1.14, \mathrm{~s}$ & $1.00, \mathrm{~s}$ \\
\hline 15 & $1.02, \mathrm{~s}$ & $1.22, \mathrm{~s}$ & $1.25, \mathrm{~s}$ & $0.99, \mathrm{~s}$ & $1.22, \mathrm{~s}$ & $1.04, \mathrm{~s}$ & $2.01, \mathrm{dd}(1.3,1.2)$ \\
\hline $\mathrm{OCH}_{3}$ & & & & & & $3.47, \mathrm{~s}$ & $3.27, \mathrm{~s}$ \\
\hline
\end{tabular}

${ }^{a}$ Data were collected at $600 \mathrm{MHz}$ in methanol- $d_{4} \cdot{ }^{b}$ Data were collected at $600 \mathrm{MHz}$ in $\mathrm{CDCl}_{3}$. 
Table 2.

${ }^{13} \mathrm{C}$ NMR Spectroscopic Data $\left(\delta_{\mathrm{C}}\right)$ for Compounds 5 - 11

$\begin{array}{lrrrrrrr}\text { Position } & \mathbf{5}^{a} & \mathbf{6}^{a} & \mathbf{7}^{a, c} & \mathbf{8}^{a} & \mathbf{9}^{b} & \mathbf{1 0}^{b, c} & \mathbf{1 1}^{b, c} \\ 1 & 55.8 & 139.4 & 50.6 & 55.7 & 54.5 & 54.0 & 136.0 \\ 2 & 48.5 & 40.4 & 43.5 & 46.6 & 50.5 & 45.3 & 40.6 \\ 3 & 31.6 & 30.6 & 31.4 & 36.0 & 35.2 & 34.9 & 33.9 \\ 4 & 48.6 & 46.5 & 47.7 & 43.5 & 42.7 & 42.6 & 42.6 \\ 5 & 80.1 & 82.6 & 79.7 & 80.0 & 79.9 & 79.2 & 87.4 \\ 6 & 70.8 & 73.9 & 70.5 & 69.2 & 68.3 & 68.2 & 208.0 \\ 7 & 40.6 & 45.4 & 43.0 & 40.1 & 37.8 & 40.1 & 50.1 \\ 8 & 50.8 & 74.5 & 53.5 & 54.5 & 56.3 & 54.0 & 132.5 \\ 9 & 88.3 & 142.8 & 148.3 & 82.4 & 213.1 & 90.8 & 132.5 \\ 10 & 130.7 & 124.9 & 129.1 & 132.1 & 128.0 & 127.7 & 75.2 \\ 11 & 142.1 & 126.8 & 81.9 & 137.6 & 166.6 & 137.1 & 135.0 \\ 12 & 62.5 & 65.0 & 61.3 & 63.4 & 60.9 & 62.7 & 68.5 \\ 13 & 67.1 & 68.3 & 66.9 & 23.5 & 23.7 & 23.1 & 26.2 \\ 14 & 19.5 & 19.9 & 19.3 & 24.3 & 23.1 & 23.5 & 21.5 \\ 15 & 24.6 & 32.1 & 27.4 & 17.6 & 23.8 & 17.0 & 19.8 \\ \text { OCH }_{3} & & & & & & 58.8 & 55.5\end{array}$

${ }^{a}$ Data were collected at $150 \mathrm{MHz}$ in methanol- $d_{4} \cdot{ }^{b}$ Data were collected at $150 \mathrm{MHz}$ in $\mathrm{CDCl}_{3}$. ${ }^{c}$ Assignments were made using HSQC and $\mathrm{HMBC}$ data collected at $600 \mathrm{MHz}\left({ }^{1} \mathrm{H}\right.$ dimension). 


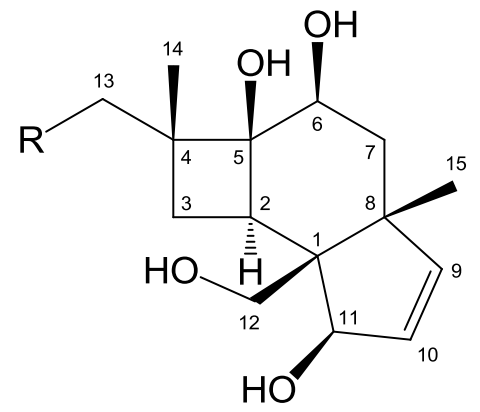

1: $\mathrm{R}=\mathrm{H}$

7: $\mathrm{R}=\mathrm{OH}$

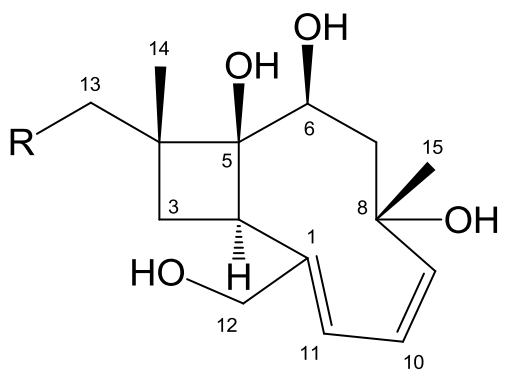

3: $\mathrm{R}=\mathrm{H}$

6: $\mathrm{R}=\mathrm{OH}$

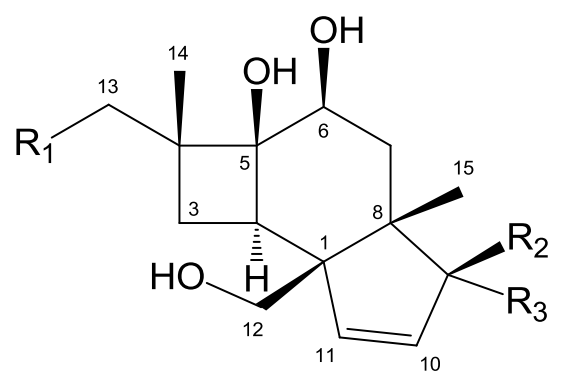

2: $\mathbf{R}_{1}, \mathbf{R}_{\mathbf{2}}=\mathrm{H} ; \mathrm{R}_{\mathbf{3}}=\mathrm{OH}$

5: $\mathbf{R}_{1}, \mathbf{R}_{3}=\mathrm{OH} ; \mathbf{R}_{2}=\mathrm{H}$

8: $\mathrm{R}_{1}, \mathrm{R}_{3}=\mathrm{H}$; $\mathrm{R}_{2}=\mathrm{OH}$

9: $\mathbf{R}_{\mathbf{1}}=\mathrm{H} ; \mathbf{R}_{\mathbf{2}}, \mathbf{R}_{\mathbf{3}}=\mathrm{O}$

10: $\mathbf{R}_{1}, \mathbf{R}_{3}=\mathrm{H} ; \mathrm{R}_{\mathbf{2}}=\mathrm{OCH}_{3}$

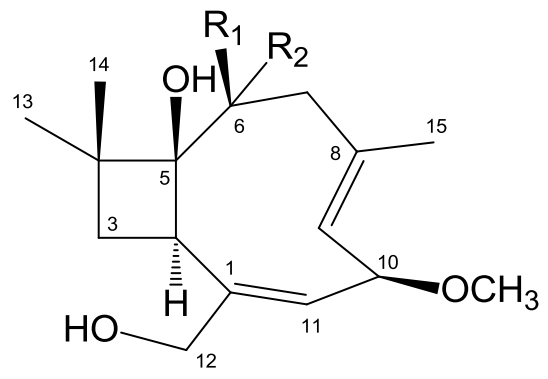

4: $\mathbf{R}_{\mathbf{1}}=\mathrm{OH} ; \mathrm{R}_{\mathbf{2}}=\mathrm{H}$

11: $R_{1}, R_{2}=0$ 
Fig. 1. Key HMBC correlations for 6,13-dihydroxypunctaporonin A (5)

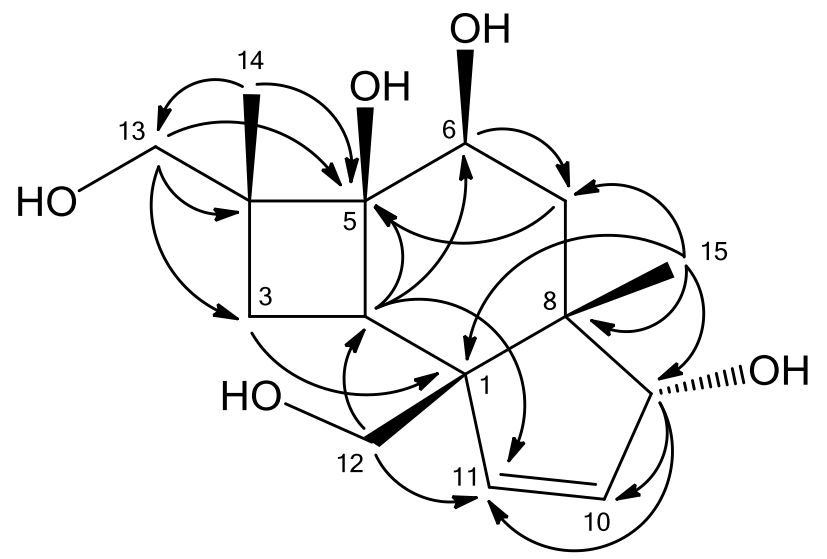


Fig. 2. Energy-minimized model and key NOESY correlations for 6,13dihydroxypunctaporonin A (5)

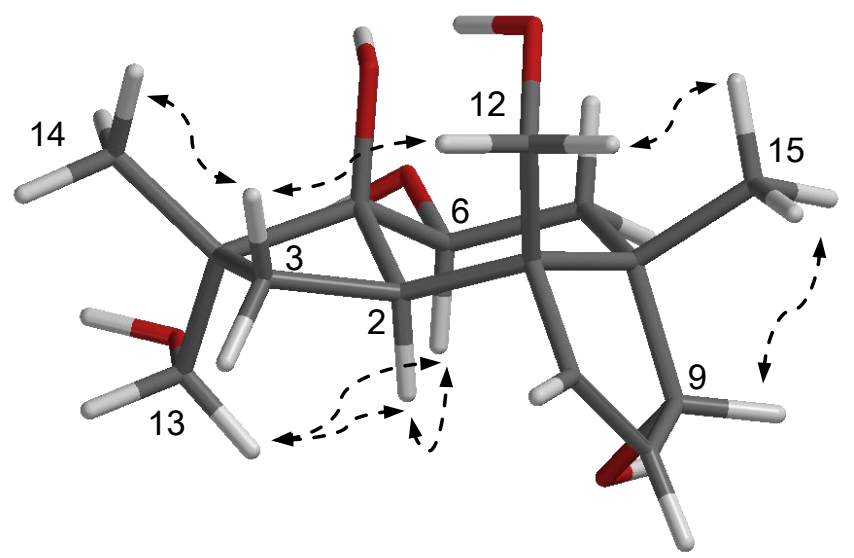


Fig. 3. Energy-minimized model and key NOESY correlations for 6hydroxypunctaporonin D (8)

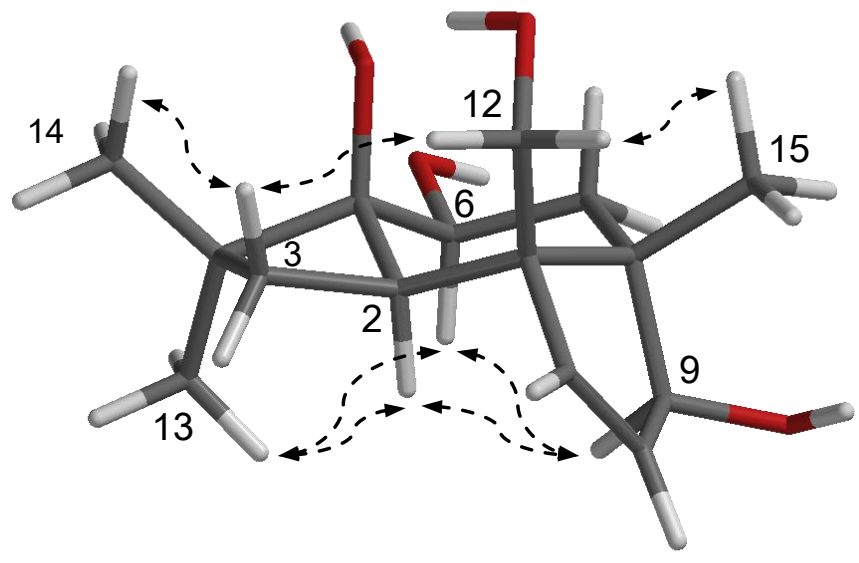




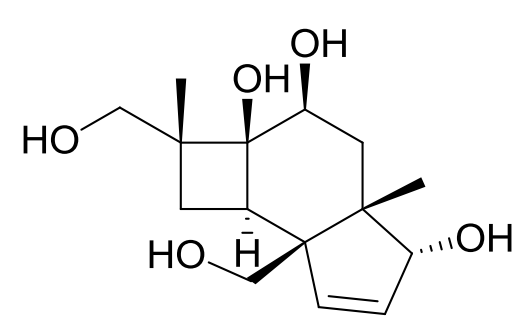

5

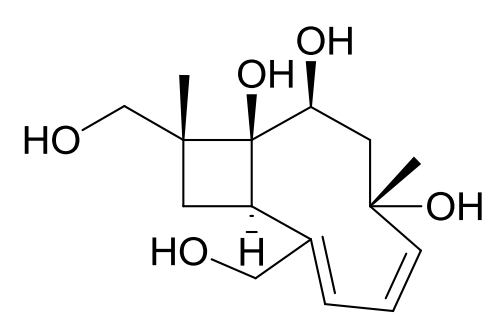

6

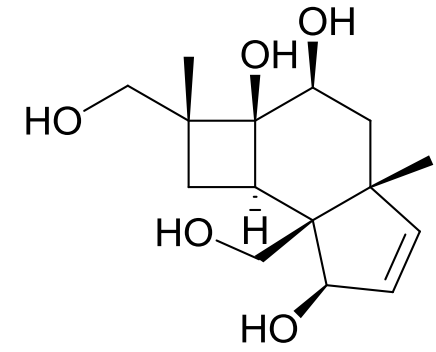

7 